\title{
Fitness evaluation of mandibular kennedy class I BioHPP Poly-Ether-Ether ketone removable partial denture fabricated by various techniques
}

\author{
Khalid Abograra Ahmad Shaban', Fatma Mahanna ${ }^{2}$, Nesreen El Mekawy ${ }^{3 *}$ \\ ${ }^{1}$ External Residence, ${ }^{2}$ Lecturer of Prosthodontics, ${ }^{3}$ Professor of Prosthodontics ${ }^{1}$ Faculty of Dentistry, Al-Jabal Al-Gharbi \\ University, Libya. ${ }^{2-3}$ Faculty of Dentistry, Mansoura University, Mansoura, Egypt \\ *Corresponding Author: Nesreen El Mekawy \\ Email: nesreen_elmekawy@yahoo.com
}

\begin{abstract}
Purpose: The purpose of this study was to evaluate the fitness of mandibular Kennedy class I PEEK removable partial dentures fabricated with various techniques.

Materials and Methods: Six patients were selected for this study with maxillary completely edentulous arch against mandibular distal extension ridges posterior to canine teeth. each patient was randomly given the following frameworks in a crossover design; Group I: All patients were received PEEK frameworks fabricated by milling via CAD-CAM technique (PEEK disc were used). Group II: All patients were received PEEK frameworks fabricated by injection molding technique (Granular form of medical grade PEEK). For each framework (milled \& injected), the fitness evaluation were done by measuring the gap between the framework and oral structures by evaluation the thickness of light body poly vinyl- siloxane impression material.

Results: The mean overall and site specific values of Gap distance beneath frameworks fabricated by CAD-CAM technique was significantly higher than the mean values of Gap distance in frameworks fabricated by injection technique.

Conclusion: Within the limitations of this short-term clinical study it was concluded that: 1) The fitness of both techniques of the RPD PEEK BioHPP frameworks manufacture were clinically accepted by the participants. 2) The RPD PEEK BioHPP frameworks manufactured by CAD / CAM was less fitness values than BioHPP frameworks constructed by Injection molding technique.
\end{abstract}

Keywords: Kennedy class I, Polyetheretherketone, CAD/CAM technique, Injection mold technique, Removable partial denture fitness.

\section{Introduction}

Removable partial dentures (RPDs) are rational treatment modality that is used to replace missing teeth in patients with partial edentulism to reestablish efficacy of mastication, esthetics and phonetics. ${ }^{1,2}$ The RPD is a treatment option that can improve the life quality for millions of patients worldwide; ${ }^{3}$ Compared with more costly alternatives, RPDs were preferred with limited financial issues in lower socioeconomic status, and to overcome the pragmatic concerns such as bio-mechanical issues related with dental implants. ${ }^{4}$ Furthermore, RPDs considered as greatest practical treatment for many clinical situations, like replacement of lost hard and soft tissues that result in a need for esthetic support of the orofacial structures, transitional prostheses for the failing dentition, and long edentulous spans. ${ }^{5}$
Proper design, component selection, and materials, follow up together with Patient's acceptance are consideredmain factors for RPD success. ${ }^{6}$ In traditional removable dental prostheses RPPs that fabricated by conventional techniques, a cheap frameworks constructed with cobalt chromium frameworks have been an expectable choice for partially edentulous patients rehabilitation. ${ }^{7}$ However, conventional RPD drawbacks as the multiple steps, time consuming technique, together with visually undesirable metallic display of clasps, the possible metallic taste, the increased RPD weight, and sensitivity to metallic components, enforced the need for alternative. ${ }^{8-10}$

Further progress regarding materials, introduced polymer-based materials that provide a beneficial improvement over conventional materials. Poly-etherether-ketone (PEEK) has been widely applied in 
medical field over the last years. ${ }^{11}$ Recently, PEEK has been suggested for dental applications. A modified PEEK (BioHPP) material containing 20\% ceramic fillers is a high performance polymer, which presents high biocompatibility, good mechanical properties, high temperature resistance, and chemical stability. ${ }^{12-14}$ Moreover; esthetically, "BioHPP" frameworks have a white color, which offers an alternative approaches in appearance compared to that metal display of traditional frameworks. Further useful benefits of such polymer material include absence of metallic taste and allergic responses, high polishing qualities, low plaque attraction, and good wear resistance. ${ }^{15}$

BioHPP with a great potential as framework material, makes good alternative to $\mathrm{Cr}$-Co frameworks in patients with high aesthetic requirements. Owing to its mechanical properties PEEK BioHPP can be used to construct clasps and dentures by CAD CAM systems. ${ }^{16}$ On other hand, PEEK components can be manufactured using injection molding, extrusion and compression molding techniques. ${ }^{17}$

Intimate contact between the RPD components contact intimately to the underlying oral tissue. It provide greater support, retention, and stability; beside the wide range of mucosal coverage of the RPD. ${ }^{18}$ Different approaches are used for evaluation of fit accuracy in RPD frameworks. ${ }^{19}$ Techniques such as replication with poly vinyl silicon have been applied in various studies. ${ }^{20-22}$ However, only few number of studies have make an effort to estimate the fitness of RPD frameworks constructed by CAD/CAM technique either "directly", where the entire framework is constructed via CAD/CAM, or "indirectly", constructed by injection molding, extrusion and compression molding techniques.

And so, the purpose of this study was to evaluate the fitness of Mandibular Kennedy Class I BioHPP PEEK RPD frameworks fabricated by CAD/CAM and injection molding techniques.

\section{Materials and Methods Study population}

This study was carried out on six participants with age group ranged between $40-60$ years, (mean age 50 years). These participants were selected according to the following criteria: They were free from systemic diseases related to bone resorption as Diabetes Mellitus and osteoporosis achieved by physician, They had a good oral hygiene and, had completely edentulous maxilla opposed to partially edentulous mandible with remaining six anterior teeth only free from periodontal affection, and the crown-root ratio of the abutment was more than 1:1.

\section{Ethical approval}

All study steps were explained to participants who were asked to sign informed written consents. The study protocol and methods were approved by Dental Research Ethical Committee of faculty of dentistry, Mansoura University under number (070805/8).

\section{Randomization}

Randomization of the study was done by listed Patients'names on Excel sheet (Microsoft, USA) and sorted randomly for two groups.

\section{Pre-Prosthetic procedures}

All participants were examined clinically and radiographically to Verify inclusion criteria. Panoramic and periapical radiograph for abutments were captured to assure crown-root ratio. Periodontal therapies (scaling / pocket eradication) were done.

\section{Prosthetic procedures}

For every patient primary impressions for both arches were made using Alginate impression material, Cavex, Netherlands. Holland). The mandibular study cast (Fig. 1), for each case were secured on the scanning machine a 3D scanner to obtain a simulated models for all cases, which were digitally surveyed to conclude the more suitable inserting pathway, and to plan the needed mouth preparation.

The designs of cases' frameworks were planned including; lingual plate major connector to enhance the resistance to torsional forces applied by the RPD's distal extension, I bar direct retainer on both canines bilaterally (The average thickness of the designed I bar in this study was $1.5 \mathrm{~mm}$ ), and cingulum rests on both canines too. The abutments were prepared to receive different components of RPD framework as following: Proximal guiding planes of $1 \mathrm{~mm}$ occluso-gingival height were prepared on distal surface of mandibular 
canines, cingulum rest seats were prepared on mandibular canines to receive cingulum rest.

Maxillary and mandibular secondary impressions were made by (Medium body Elastomeric impression material); maxillary impression was poured with hard stone to produce the master model, while the mandibular impressions were poured master models for construction of both types of RPD frameworks. The definitive mandibular cast of each case was then secured to the scanner, and scanned to get the standard triangulation (STL) (Fig. 2) file which was then transferred to the designing software to begin the process of designing.

Desirable undercut areas were used for I- bar clasp retention on the disto-buccal surface of the abutment teeth. Selection of framework constituents were done from the library's list of options and positioned in the right place in the formula of linked dots (Fig. 3). The width and thickness of any portion of each constituent can be altered. For each case a tentative stereolithographic resin framework was made using rapid prototyping technology to verify the designed framework intraorally before manufacturing the final frames.

\section{Participants groups}

The enrolment participants were assigned into one of the two study groups according to the fabrication techniques: Group I: All Patients received PEEK frameworks fabricated by milling via CAD-CAM technique (PEEK disc were used); while, Group II: All Patients received PEEK frameworks fabricated by injection molding technique (Granular form of medical grade PEEK).

For the first group, after the 3D printed resin frameworks were found satisfactory intraorally, for each case the 3D design was introduced directly to manufacturing compartment to begin the "milling" process of BioHPP (BioHPP, Bredent $\mathrm{GmbH}$ ) dental discs directly to the desired design. The PEEK BioHPP framework was then removed from disc using carbide bur, and checked in the mouth.

For the second group, after the fitting of the 3D printed resin frameworks intraorally, the 3D design was milled into wax blocks, to accomplish best injection outcomes. Each wax model was adapted to its master cast and, invested The mold is pre-heated up to $630^{\circ} \mathrm{C}-850^{\circ} \mathrm{C}$, for wax melting and controlling expansion of the investment material and then cooled at $400^{\circ} \mathrm{C}$ which is melting range of BioHPP. After complete melting of PEEK BioHPP granules, press plunger is inserted in the cylindrical reservoir, the investment mold transferred to (for 2-press system). The procedure is completed fully automatically within 35 minutes, the mold then left to cool and devested as usual (Fig. 4). The frameworks then disconnected from sprues and finished in usual manner.

\section{Evaluation of PEEK Bio HPP frame works fitness for both groups}

Evaluation of PEEK BioHPP frameworks for both groups fitness were done by measuring the gap between the frameworks and oral structures. Evaluation the thickness of light body poly vinylsiloxane (Zhermack, Badia Polesine (Rovigo)-Italy) impression material (orange in color) using digital poly-gauge. $^{20}$

The thickness of PEEK BioHPP frameworks were measured at predetermined three points at (Major connector, cinglum rests, clasps, and Guiding planes) before using the impression material. The fitness was examined through the following steps: 1 . drying of the intaglio surface of PEEK BioHPP frameworks; 2. mixing of the poly vinyl-siloxane material; 3 . Spread the material on the intaglio surface of the framework; 4. Framework was seated intra-orally, force applied on three points (the two principle cinglum rests and the third point on major connector's midpoint) until complete impression set. Remove The framework from the patien's mouth with impression material (Fig. 5 ), measured again at the same predetermined points, The difference in digital poly-gauge reading at each point represents the added thickness of Light body poly vinyl-siloxane impression material that fill the gap between the framework and the oral structures. These readings were collected and tabulated and subjected to statistical analysis.

\section{Statistical analysis and data interpretation}

All Records were served to the computerized processor and evaluated via "IBM SPSS" type 22.0. Measurable statistics were defined by "X" \& "SD" for 
parametric data after testing "normality" using Shapiro-Wilk test. Paired t test to compare between 2 techniques in the same patient.

\section{Results}

Table 1 Figure 6 revealed Paired t test to compare the mean Gap distance between, CAD/CAM and injection techniques among studied groups. A statistically significantly difference between CAD/CAM technique group \& Injection technique group as regard to Gap distance mean score with higher mean score among $\mathrm{CAD} / \mathrm{CAM}$ group than injection molding group (0.48 \pm $0.02 \& 0.31 \pm 0.025$, respectively). The more Gap distance means less fitness.

Table 1: Comparison of mean Gap distance between, $\mathrm{CAD} / \mathrm{CAM}$ technique and injection molding technique among studied groups

\begin{tabular}{|c|c|c|c|}
\hline \multicolumn{3}{|c|}{ Gap distance in millimeter } & \\
\hline & $\begin{array}{c}\text { CAD/CAM } \\
\text { technique }\end{array}$ & $\begin{array}{c}\text { Injected molding } \\
\text { technique }\end{array}$ & $\begin{array}{c}\text { Test of } \\
\text { significance }\end{array}$ \\
\hline $\begin{array}{c}\mathrm{X}^{\top} \\
\pm \mathrm{SD}\end{array}$ & $0.48 \pm 0.02$ & $0.31 \pm 0.025$ & $\mathrm{p}=0.001^{*}$ \\
\hline
\end{tabular}

SD: standard deviation, X: mean, P: Probability $*$ :significance $<0.05$
Table 2 compared the mean Gap distance of $\mathrm{CAD} / \mathrm{CAM}$ and Injected molding technique in specific sites concerning major connector, rest, Clasp and, Guiding plane. Regarding the Major connector, the mean value of Gap distance in Group I (CAD/CAM technique) was $0.37 \pm 0.05$, and in group II (Injection molding technique) it was $(0.18 \pm 0.05)$. Therefore Gap distance of major connector was higher in "Group" I than II. Substantial variance among them $(\mathrm{p}=0.003)$, which indicate more fitness of injected frames at considered region. Similarly, the mean Gap distance of Rest, Clasp, and Guiding plane of Group I were $(0.28 \pm 0.03,0.18 \pm 0.02 \& 0.11 \pm 0.01)$ respectively; Where in Group II were $(0.12 \pm 0.04,0.083 \pm 0.01 \&$ $0.09 \pm 0.01)$. Regarding the three different sites Group I exhibit significant higher mean values than Group II, which means that injected molding frames were more fit than milled frames at these specific sites. Moreover, among all of previous frames parts related to teeth, Major connector show the highest mean Gap distance in both groups.

Table 2: Comparison of mean site specific Gap distance, between, (CAD/CAM and injection molding techniques) among studied groups.

\begin{tabular}{|c|c|c|c|}
\hline Gap distance & $\begin{array}{c}\text { CAD/CAM technique } \\
n=6\end{array}$ & $\begin{array}{l}\text { Injection molding technique } \\
\qquad n=6\end{array}$ & $\begin{array}{c}\text { Test of } \\
\text { significance }\end{array}$ \\
\hline Major connector & $0.377 \pm 0.05$ & $0.18 \pm 0.05$ & $\begin{array}{c}\mathrm{t}=5.25 \\
\mathrm{p}=0.003^{*}\end{array}$ \\
\hline Rest & $0.28 \pm 0.03$ & $0.12 \pm 0.04$ & $\begin{array}{l}\mathrm{t}=13.68 \\
\mathrm{p}=0.001 *\end{array}$ \\
\hline Clasp & $0.18 \pm 0.02$ & $0.083 \pm 0.01$ & $\begin{array}{c}\mathrm{t}=16.36 \\
\mathrm{p}<0.001 *\end{array}$ \\
\hline Guiding plane & $0.11 \pm 0.01$ & $0.09 \pm 0.01$ & $\begin{array}{c}\mathrm{t}=2.89 \\
\mathrm{p}=0.03^{*}\end{array}$ \\
\hline
\end{tabular}

SD: standard deviation, X: mean, P: Probability *: significance $<0.05$ 


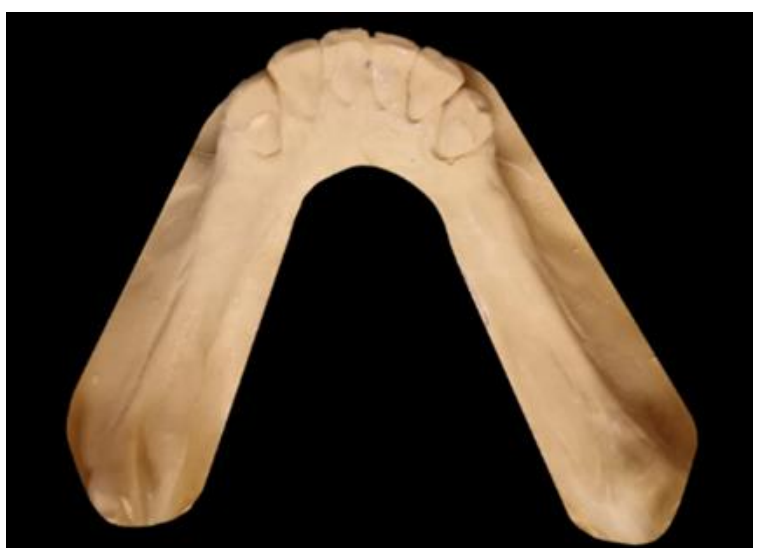

Fig. 1: The mandibular study cast

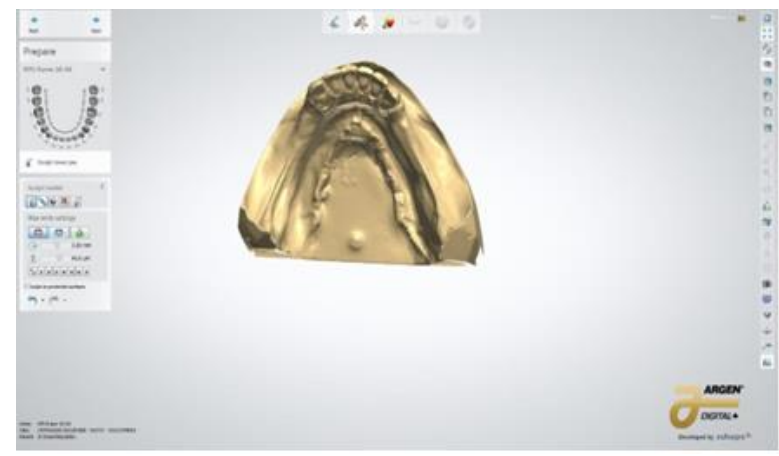

Fig. 2: Scanned3Dstandard triangulation (STL) of definitive cast
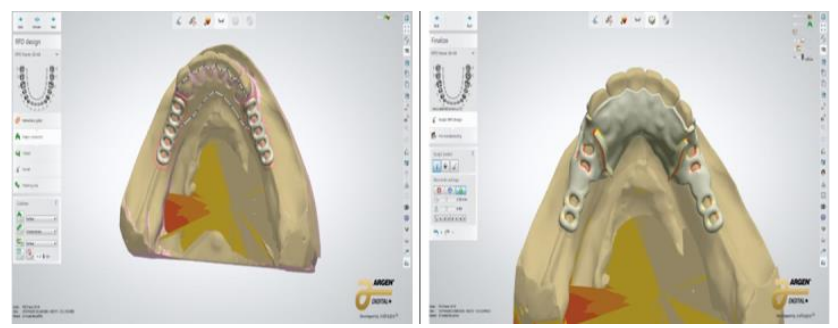

Fig. 3: All components of the framework were selected from a menu and placed

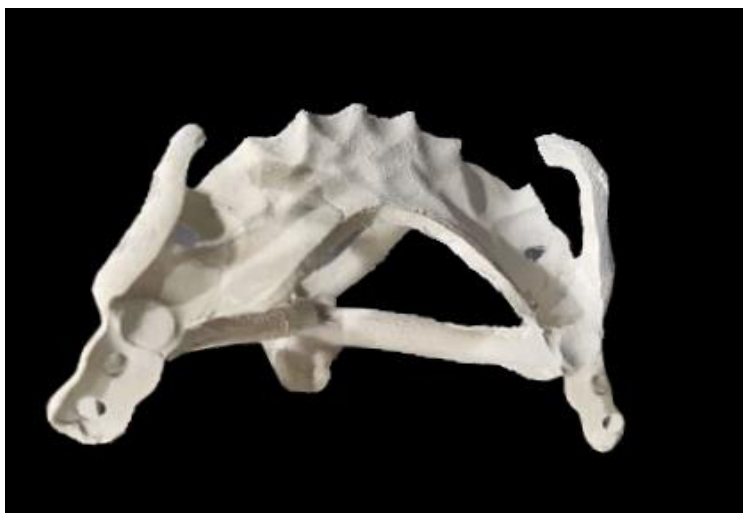

Fig. 4: The Injection molding framework attached to the sprues before finshing

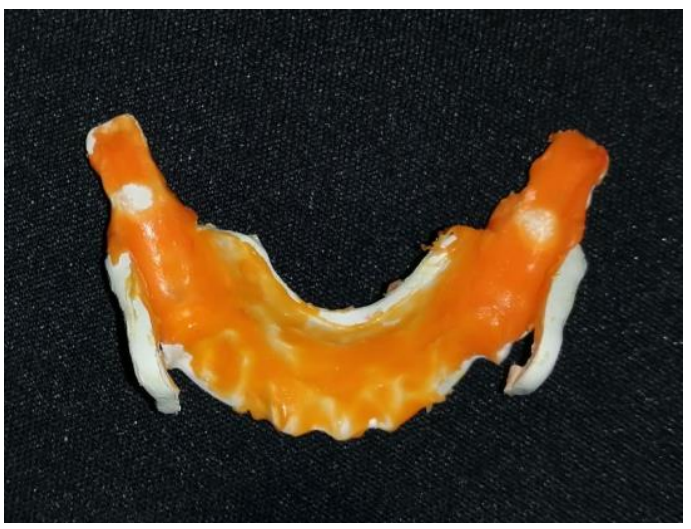

Fig. 5: The RPD framework with poly vinyl-siloxane impression material

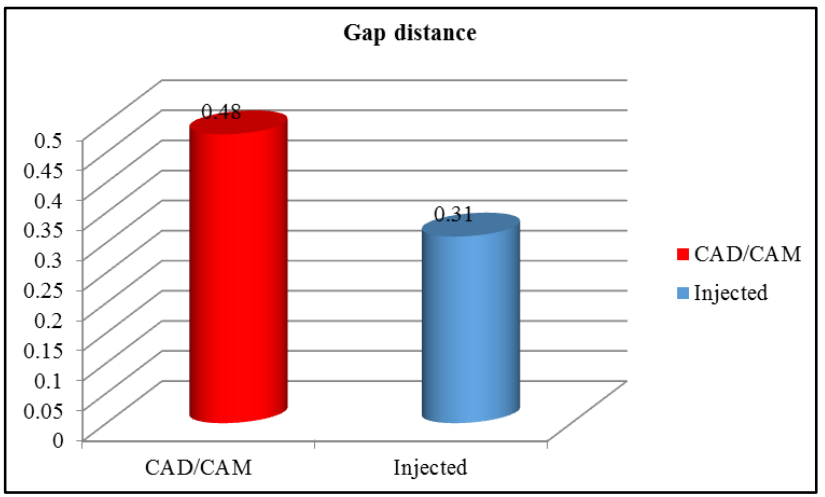

Fig 6: Comparison of overall gap distance score between CAD/CAM frameworks \& Injection molding frameworks among studied cases

\section{Discussion}

Only few studies ${ }^{23,24}$ have estimated the fitness of PEEK BioHPP frameworks constructed via two different methods. In respect to both techniques, the patients were satisfied regarding the fitness accuracy, "light weight" of their RDPs and the "white shade" of the frame-works; which was in agreement with Zoidis et al., ${ }^{13}$ who used BIO HPP framework as alternative to traditional cobalt chromium and demonstrate patient acceptance and satisfaction; and with Ichikawa et al., ${ }^{25}$ who used non-filler poly-ether-ether-ketone (PEEK) to construct the RPD (retaining clasps) for the mandibular kennedy class I of an 84-year-old female. Two years follow-up subjective satisfaction was expressed by patient.

In this study; polyvinyl siloxane material was used for fitness evaluation by measuring the space between PEEK BioHPP frameworks and the underlining tissue as well as to detect any areas of compression. Polyvinyl siloxane was used as it can be read easily and its removal was quite simple, offer a 3D perspective, and has slight width as reported by Gan et al., ${ }^{22}$ who evaluated the adaptation of the removable 
prosthesis by measuring the gaps between the metal framework components and the supporting tissues.

Beneath each PEEK BioHPP frameworks placed in participant's mouth, there was a gap for the used impression material. The overall adaptation ranged from.908 $\mu \mathrm{m}$ to $958 \mu \mathrm{m}$ for group I (BioHPP frameworks constructed by CAD/CAM technique) and from $927 \mu \mathrm{m}$ to $991 \mu \mathrm{m}$ for group II (BioHPP frameworks constructed by Injection molding technique). In an early study by Rantanen and, Eerikäinen $^{26}$ concerned to traditionally casted "maxillary" RPDs, it was adapted from (0.11 - 0.93) $\mathrm{mm}$ in participant's oral cavity. While Diwan et al. ${ }^{18}$ stated that the mean value of adaptation was $(0.64 \pm$ $0.07) \mathrm{mm}$ for the "modified palatal plate" and (0.56 \pm $0.04) \mathrm{mm}$ for the "palatal strap" on cast models, correspondingly.

In this study, the mean of overall fitness (gap distance) indicate that frameworks Injection molding technique were significantly, more fit than those with CAD/CAM (milling), where the first group was $(0.31 \pm 0.025)$ and the second group was $(0.48 \pm 0.02)$ respectively. This may be due to the flow ability of injected molten BioHPP and its intimate adaptation to cast details under pressure. Interestingly, milling technique showed the highest variability in thickness and distribution especially at major connector areas, this may result as computer aided design may ignore certain blocked areas of undercut. Furthermore, Srinivasan et $\mathrm{al}^{27}{ }^{27}$ mentioned that the intaglio surface of a CAD/CAM milled denture is not smooth, but rather "terraced, Inevitably, the size of the milling instrument determines the smoothness of the fit surface.

Concerning, of region specific mismatch, rest and guiding plane in this study have found to be more fitted in injected tech than milling technique $(0.12$, $0.09>0.28,0.11)$ respectively, and this was in agreement with Negm et al. ${ }^{28}$ Who found that the fitness of injected rest and guiding plane were $(0.05$, $0.04)$ while of milled were $(0.07,0.08)$ respectively.

The result of this study found that the gap distance between the major connector and supporting tissues in group I was $0.377 \pm 0.05$ while in group II was $0.18 \pm 0.05$. These results were associated with the manufacturing procedures and the probable reasons of misfit related to casting procedures as reported by Negm et al. ${ }^{28}$ The thickness of the major connector may have influence on the accuracy of fit, so it is suggested that future studies reduce the framework thickness.

RPD's CAD software requires appropriate function equipment and more improvement to get enhanced adaptation to the clinical demands. Similarly additional improvement can be created such as establishing soft tissues 3D database for both maxillary and mandibular arches. Consequently, during RPD framework design step, the software can provide a prediction about the difference in soft tissues flexibility degree at varied areas and decrease the thickness of altered soft tissues beside the normal direction in an automatic way, simulating the effect of pressure impressions.

Furthermore, additional long-term clinical studies are required to identify the precise location of gaps or compression and define whether these outcomes were in the suitable clinical range. Additionally, given the restrictions of consuming single material in the frameworks construction, the authors propose prospective studies to estimate the fitness by using different materials.

\section{Conclusions}

Within the limitations of this short-term clinical study it was concluded that:

1. The fitness of both techniques of the RPD PEEK BioHPP frameworks manufacture were clinically accepted by the participants

2. The RPD PEEK BioHPP frameworks manufactured by CAD / CAM was less fitted than BioHPP frameworks constructed by Injection molding technique.

\section{Source of Funding}

None.

\section{Conflict of Interest}

None.

\section{References}

1. Campbell SD, Cooper L, Craddock H, Hyde TP, Nattress B, Pavitt SH, Seymour DW et al. Removable partial dentures: The clinical need for innovation. J Prosthet Dent 2017;118:273-80.

2. Picos AM, Donca V, Picos A. Prosthetic Rehabilitation in Partially Edentulous Elders - A Case Report. Clujul Med 2014:87:203-6.

3. Inayat N, Das G, Rana MH, Reehana, Munir N. Oral health; compare the percentage decrease in score of oral health related quality of life in patients provided with removable partial dentures and fixed partial dentures. Professional Med J 2018;25:997-1004.

4. Bohnenkamp DM. Removable partial dentures: clinical concepts. Dent Clin 2014;58:69-89.

5. Benso B, Kovalik AC, Jorge JH, Campanha NH. Failures in the rehabilitation treatment with removable partial dentures. Acta Odontol Scand 2013;71:1351-5.

6. Koyama Sh, Sasaki K, Yokoyama M, Sasaki T, Hanawa S. Evaluation of factors affecting the continuing use and 
patient satisfaction with Removable Partial Dentures over 5 years. J Prosthodont Res 2010;54:97-101.

7. Suwal P, Singh R, Aye, A, RoyD, Roy R. Cast Partial Denture versus Acrylic Partial Denture for Replacement of Missing Teeth in Partially Edentulous Patients. JDMT 2017;6:27-34.

8. Turagam N, Mudrakola DP, Yelamanchi RS, Deepthi M, Natarajan M. Esthetic Clasp Cast Partial Denture. J Int Soc Prev Community Dent 2019;9: 94-8.

9. El Mekawy N, Gad E. Retentive force and surface roughness of partial removable frameworks fabricated from conventional chrome-cobalt and cad / cam modified polyetheretherketone materials (within-subject evaluation). Egypt Dent J 2016;62:5055-62.

10. Ito M, Wee AG, Miyamoto T, Kawai Y. The combination of a nylon and traditional partial removable dental prosthesis for improved esthetics: a clinical report. $J$ Prosthet Dent 2013;109:5-8.

11. Panayotov I, Orti V, Cuisinier F, Yachouh J. Polyetheretherketone (PEEK) for medical applications. $J$ Mater Sci Mater Med 2016;27:118.

12. Bathala L, Majeti V, Rachuri N, Singh N, Gedela S. The Role of Polyether Ether Ketone (PEEK) in Dentistry - A Review. J Med Life 2019;12:5-9.

13. Zoidis P, Papathanasiou I, Polyzois G. The Use of a Modified Poly-Ether-Ether-Ketone (PEEK) as an Alternative Framework Material for Removable Dental Prostheses: A Clinical Report. J Prosthodont 2016;25:5804.

14. Benakatti V, Sajjanar J, Acharya A. Polyetheretherketone (PEEK) in Dentistry. J Clin Diagn Res. 2019; 13: ZE10ZE12.

15. Andrikopoulou E, Zoidis P, Artopoulou I, Doukoudakis A. Modified PEEK Resin Bonded Fixed Dental Prosthesis for a Young Cleft Lip and Palate Patient. J Esthet Restor Dent 2016;28:201-7.

16. Skirbutis G, Dzingute A, Masiliunate V, Sulcaite G, Zilinskas J. A review of PEEK polymer's properties and its use in prosthodontics. $J$ Stomatologia Baltic and Maxillofac 2017; 19:19-23.

17. Kurtz SM. PEEK Biomaterialsf Handbook; Elsevier Science: Waltham, MA, USA, 2012; pp2.

18. Diwan R, Talic Y, Omar N, Sadiq W. The effect of storage time of removable partial denture wax pattern on the accuracy of fit of the cast framework. $J$ Prosthet Dent 1997; 7:375-81.

19. Shetty MS, Shenoy KK. Techniques for evaluating the fit of removable and fixed prosthesis. ISRN Dent 2011;2011:14

20. Gowri V, Patil NP, Nadiger RK, Guttal S. Effect of anchorage on the accuracy of fit in removable partial denture framework. J Prosthodont 2010;19:387-90

21. Lee JW, Park JM, Park EJ, Heo S, Koak J, Kim S et al. The accuracy of a digital removable partial denture fabricated by casting a rapid-prototyped pattern: a clinical study. $J$ Prosthet Dent 2017;118:468-74

22. Gan N, Ruan Y, Sun J, Xiong Y, Jiao T. Comparison of adaptation between the major connectors fabricated from intraoral digital impressions and extraoral digital impressions. Sci Rep 2018;8:529.

23. Arnold C, Hey J, Schweyen R, Setz J. The accuracy of CAD-CAM-fabricated removable partial dentures. $J$ Prosthet Dent 2018;119:586-92.

24. Soltanzadeh P, Suprono M S, Kattadiyil M.T, Goodacre C. and Gregorius W. An in vitro investigation of accuracy and fit of conventional and CAD/CAM removable partial denture frameworks. J Prosthodont 2019;28:547-55.

25. Ichikawa T, Kurahashi K, Liu L, Matsuda T, Ishida Y. Use of a Polyetheretherketone Clasp Retainer for Removable Partial Denture: A Case Report. Dent J 2019;7(1):4.

26. Rantanen T. \& Eerikäinen E. Accuracy of the palatal plate of removable partial dentures, and influence of laboratory handling of the investment on the accuracy. Dent Mater 1986;2:28-31.

27. Srinivasan M, Cantin Y, Mehl A, Gjengedal H, Müller F, Schimmel M. CAD/CAM milled removable complete dentures: an in vitro evaluation of trueness. Clin Oral Investigations 2017;21:2007-19.

28. Negm EE, Aboutaleb FA, Alam-Eldein AM. Virtual Evaluation of the Accuracy of Fit and Trueness in Maxillary Poly (etheretherketone) Removable Partial Denture Frameworks Fabricated by Direct and Indirect CAD/CAM Techniques. J Prosthodont 2019;28:804-10

How to cite this article: Shaban KAA, Mahanna F, EI Mekawy N. Fitness evaluation of mandibular kennedy class I BioHPP Poly-Ether-Ether ketone removable partial denture fabricated by various techniques. Ann Prosthodont Restor Dent 2019;5(4):97-103. 